\title{
Complete disappearance of lung abnormalities on high-resolution computed tomography: A case of histiocytosis $\mathrm{X}$
}

\author{
Sergio Negrin-Dastis $M D^{1}$, Dominique Butenda $M D^{1}$, Jacques Dorzee $M D^{2}$, \\ Jacques Fastrez $M D^{3}$, Jean-Paul d'Odémont $M D^{1}$
}

\begin{abstract}
S Negrin-Dastis, D Butenda, J Dorzee, J Fastrez, J-P d'Odémont. Complete disappearance of lung abnormalities on highresolution computed tomography: A case of histiocytosis X. Can Respir J 2007;14(4):235-237.

A case of pulmonary Langerhans cell histiocytosis, proved by both lung high-resolution computed tomography and lung biopsy, is described. Following smoking cessation, lung nodules and cysts gradually disappeared on serial computed tomography scans, with complete clearance of the lesions after 12 months. The role of tobacco smoking is discussed, in detail, against the background of the literature.
\end{abstract}

Key Words: Cysts; Histiocytosis X; HRCT resolution; Smoking cessation

Dulmonary Langerhans cell histiocytosis (PLCH) is an uncommon interstitial lung disease of unknown etiology. The natural history of the disease is not unknown but variable, ranging from reports of asymptomatic radiography to recurrent lung transplantations. It is usually present in young cigarette smokers, because more than $90 \%$ of patients have a history of tobacco use. We present a patient who had complete disappearance of lung abnormalities on high-resolution computed tomography (HRCT) following smoking cessation.

\section{CASE PRESENTATION}

A 50-year-old man was admitted to our Department of Pneumology, Belgium, because of a nonproductive cough that had lasted several months. The patient had a history of severe esophagitis and chronic gastritis. An appendectomy and a hemorrhoidectomy had been performed previously. There was no recent history of weight loss or recent medication intake. The patient had a 60 pack-year history of cigarette consumption, and was self-employed in a factory with no known occupational exposures.

A physical examination showed no lymphadenopathy or cutaneous abnormalities. Heart sounds were normal, and the lungs were clear. An abdominal examination was normal, and no organomegaly or masses were evident on palpation.

Chest radiography showed bilateral and symmetrical nodular opacification with a predominance of middle- and upperlobe involvement. An HRCT confirmed the presence of multiple nodules, some having central cavitation, with a few irregularly shaped cysts ( $1 \mathrm{~mm}$ to $5 \mathrm{~mm}$ in diameter) and sparing of the costophrenic angles (Figure 1A). Functional lung

\section{La disparition complète d'anomalies pulmonaires à la tomodensitométrie haute résolution : Un cas d'histiocytose $\mathrm{X}$}

On décrit un cas d'histiocytose pulmonaire de Langerhans, démontré à la fois par tomodensitométrie pulmonaire haute résolution et par biopsie pulmonaire. Lorsque le patient a cessé de fumer, les nodules et les kystes pulmonaires se sont graduellement dissipés aux tomodensitométries sérielles, et les lésions avaient complètement disparu au bout de 12 mois. On aborde longuement le rôle du tabagisme par rapport aux antécédents contenus dans les publications scientifiques.

\footnotetext{
${ }^{1}$ Department of Pneumology; ${ }^{2}$ Department of Radiology; ${ }^{3}$ Department of Thoracic Surgery, CHR St-Joseph-Warquignies, Belgium

Correspondence and reprints: Dr Jean-Paul d'Odémont, Department of Pneumology, CHR St-Joseph-Warquignies, 5-Avenue Baudouin de

Constantinople, 7000 Mons, Belgium. Telephone 065-359177, fax 065-359060, e-mail dod@skynet.be
} 

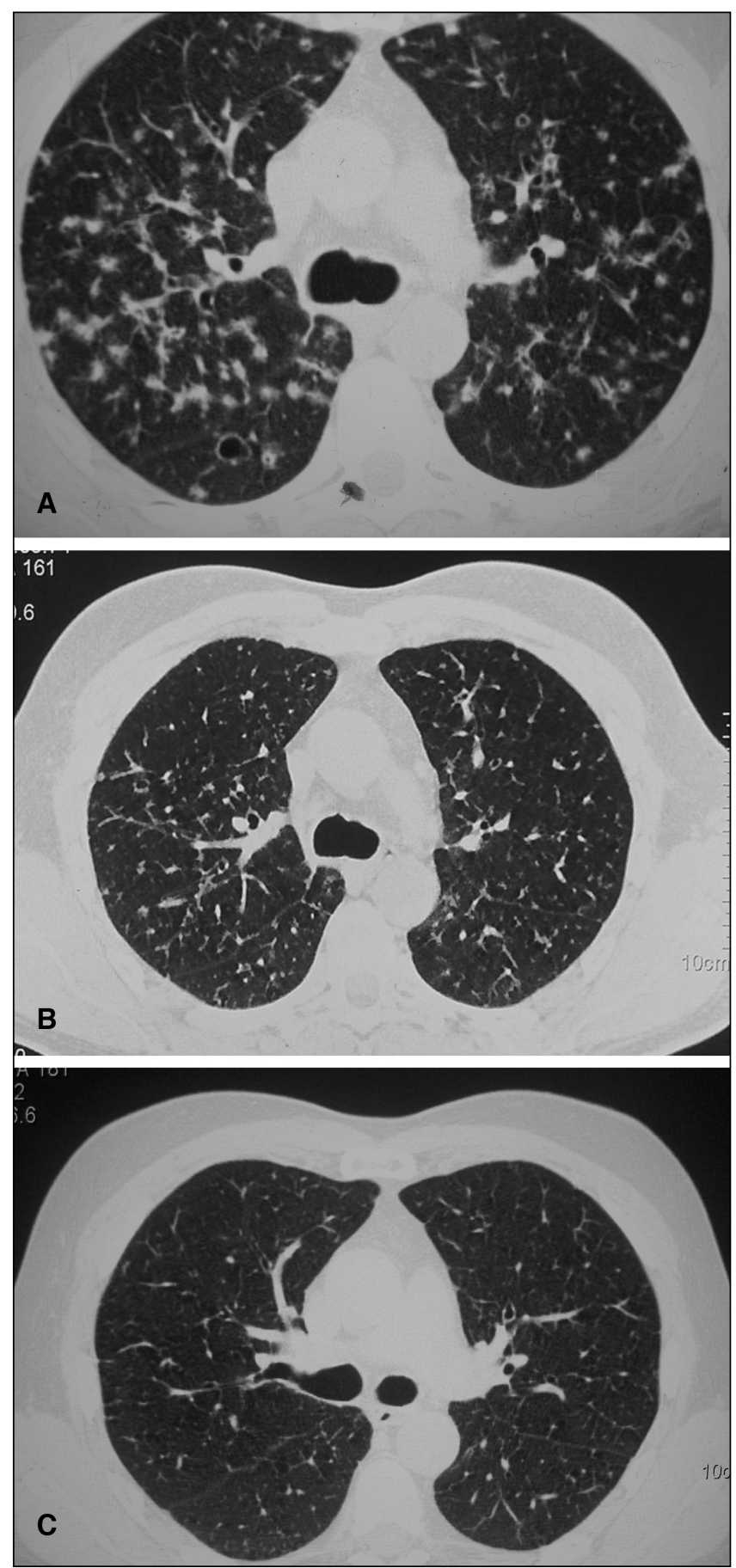

Figure 1) High-resolution computed tomography of the middle lung zones of nearly the same sections, at different times over the 12-month follow-up. A Bilateral nodular lesions with thick-and thin-walled cysts. B Reduction in size and number of nodules and cysts four months after smoking cessation. C Complete disappearance of abnormalities 12 months after smoking cessation, with evidence of centrilobular emphysema

and after three months of successful smoking cessation, the cough had completely disappeared. Four months after smoking cessation (Figure 1B), sequential lung HRCT was performed, which showed a dramatic decrease in parenchymal abnormalities. Twelve months after smoking cessation (Figure 1C), the abnormalities had completely disappeared, and the patient was still asymptomatic. The functional lung tests were unchanged. At a three-year follow-up, no significant clinical, functional or radiological changes were noted.

\section{DISCUSSION}

PLCH is an uncommon disorder that is generally observed in young smokers. Its incidence and prevalence are unknown. Between $10 \%$ and $25 \%$ of patients are asymptomatic, the main symptoms being cough and dyspnea on exertion. Chest pain related to a pneumothorax is sometimes the initial symptom. Extrapulmonary symptoms (eg, cystic bone lesions and diabetes insipidus) are present in $5 \%$ to $10 \%$ of cases. The diagnosis is often suggested by radiological presentation and BAL studies. According to some clinical and radiological features, a few diseases should be considered in terms of differential diagnosis: chronic bronchitis (secondary to smoking and refluxassociated lung disease), sarcoidosis, tuberculosis, Wegener's disease, metastasis, respiratory bronchiolitis-associated interstitial lung disease and bronchiolitis obliterans with organizing pneumonia. In our patient, HRCT of the chest was very suggestive of PLCH, with parenchymal nodules and cysts distributed in both lungs and predominantly in the middle and upper lobes, sparing the costophrenic angles. The BAL analysis did not show the presence of elevated CD1a Langerhans cells, but the sensitivity of this analysis is reported to be less than $25 \%$ $(1,2)$. Electron microscopy, which can demonstrate Langerhans cells with Birbeck's bodies allowing ultrastructural confirmation of histiocytosis X, was not performed. In our patient, the diagnosis was confirmed by the presence of nodules on surgical lung biopsies, including histiocytes positive for S-100 and CD1a.

Little is known about the causation and the natural history of PLCH in adults. The only consistent epidemiological association is with cigarette smoking, because the vast majority of patients have a history of smoking (3). Additional support for this association comes from a study by Zeid and Muller (4), which showed the development of an interstitial granulomatous inflammation in mice, similar to PLCH in humans, after exposure to tobacco smoke. To date, a number of hypotheses have been proposed to account for the association between cigarette smoking and PLCH, principally the immunostimulant effect of tobacco glycoprotein (5), the bombesin-like peptide secretion (6) from neuroendocrine cells in lung macrophages, the growth of lung fibroblasts and the bronchiolocentric distribution of the lesions.

Based on a comprehensive review of the literature, there have been reports of patients showing an improvement in chest radiographic findings after smoking cessation only (7-9). However, it is well known that chest radiographs are less accurate than HRCTs for detecting pulmonary abnormalities in patients with PLCH (10). To our knowledge, only two patients have been reported with a significant improvement based on HRCT findings following smoking cessation (11); the nodules of one of the two patients completely disappeared on HRCT. Another patient with complete resolution of coalescing air wall cysts on HRCT following smoking cessation was recently published in the Japanese literature (12). What is noteworthy in our patient is the disappearance of the HRCT abnormalities 12 months after beginning the smoking cessation program, despite numerous initial thickand thin-walled cysts. Radiological resolution is, in fact, usually reported in patients with a recent onset of active disease 
with mainly nodular lesions, with cysts usually being ascribed to airway luminal enlargement due to focal destruction of the alveolar walls. The initial normality of lung volumes in our patient, as in the two other reported cases (11) without any direct or indirect signs of radiological fibrosis, is intriguing, and may constitute a significant predictive factor for radiological resolution and a favourable outcome. The impressive disappearance of the lung lesions following smoking cessation adds to the growing evidence of the role of tobacco, but nonetheless, does not confirm a close link with the disease. For example, Tazi et al (8) have reported spontaneous resolution despite smoking persistence in two patients. The extent to which smoking cessation influences the progression and the long-term prognosis of the disease is yet to be established. Furthermore, there is a lack of data on the long-term natural history of PLCH.

\section{REFERENCES}

1. Chollet S, Soler P, Dournovo P, Richard MS, Ferrans VJ, Basset F. Diagnosis of pulmonary histiocytosis $\mathrm{X}$ by immunodetection of Langerhans cells in bronchoalveolar lavage fluid. Am J Pathol 1984;115:225-32.

2. Auerswald U, Barth J, Magnussen H. Value CD-1-positive cells in bronchoalveolar lavage fluid for the diagnosis of pulmonary histiocytosis X. Lung 1991;169:305-9.

3. Vassallo R, Ryu JH, Colby TV, Hartman T, Limper AH. Pulmonary Langerhans'-cell histiocytosis. N Engl J Med 2000;342:1969-78.

4. Zeid NA, Muller HK. Tobacco smoke induced lung granulomas and tumors: Association with pulmonary Langerhans cells. Pathology 1995;27:247-54.

5. Youkeles LH, Grizzanti JN, Liao Z, Chang CJ, Rosenstreich DL. Decreased tobacco-glycoprotein-induced lymphocyte proliferation in vitro in pulmonary eosinophilic granuloma. Am J Respir Crit Care Med 1995;151:145-50.

6. Aguayo SM, Kane MA, King Te Jr, Schwarz MI, Grauer L, Miller YE. Increased levels of bombesin-like peptides in the lower respiratory tract of asymptomatic cigarette smokers. J Clin Invest 1989;84:1105-13.

7. Von Essen S, West W, Sitorius M, Rennard SI. Complete resolution of roentgenographic changes in a patient with pulmonary histiocytosis X. Chest 1990;98:765-7.
In terms of treatment, smoking cessation should be considered before any other therapeutic modalities. In symptomatic patients, corticosteroids have been reported to be beneficial, but controlled trials of treatment are lacking. However, in terms of long-term benefit and relapse, no data on the role of smoking cessation or medication have been reported. The long-term prognosis of patients, especially those with normalization of the radiological findings, as is the case in our patient, has not yet been determined. Furthermore, the observation, reported by Davidson (13), of a patient who was symptom-free for six years with radiographic resolution and an abrupt symptomatic and radiographic exacerbation, suggests the need for a careful long-term follow-up of patients with PLCH. Against this background, the recent implementation of the trial, by the Histiocytosis Association of America (the LCH-A1), is encouraging (14).

8. Tazi A, Montcelly L, Bergeron A, Valeyre D, Battesti JP, Hance AJ. Relapsing nodular lesions in the course of adult pulmonary Langerhans cell histiocytosis. Am J Respir Crit Care Med 1998;157:2007-10.

9. Morimoto T, Matsumura T, Kitaichi M. [Rapid remission of pulmonary eosinophilic granuloma in a young male patient after cessation of smoking.] Nihon Kokyuki Gakkai Zasshi 1999;37:140-5.

10. Brauner MW, Grenier P, Mouelhi MM, Mompoint D, Lenoir S. Pulmonary histiocytosis X: Evaluation with high-resolution CT. Radiology 1989;172:255-8.

11. Mogulkoc N, Veral A, Bishop PW, Bayindir U, Pickering CA, Egan JJ. Pulmonary Langerhans' cell histiocytosis: Radiologic resolution following smoking cessation. Chest 1999;115:1452-5.

12. Okubo F, Miyazaki E, Ono E, et al. [A case of pulmonary Langerhans cell histiocytosis presenting disappearance of coalescing air wall cysts after smoking cessation.] Nihon Kokyuki Gakkai Zasshi 2005;43:432-6.

13. Davidson AR. Eosinophilic granuloma of the lung. Br J Dis Chest 1976;70:125-8.

14. Histiocytosis Association of America. Current Treatment Protocols. <http://www.histio.org/site/c.kiKTL4PQLvF/b.1767369/k.AAF9/ Current_Treatment_Protocols.htm > (Version current at April 27, 2007). 


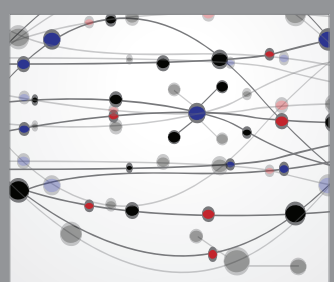

The Scientific World Journal
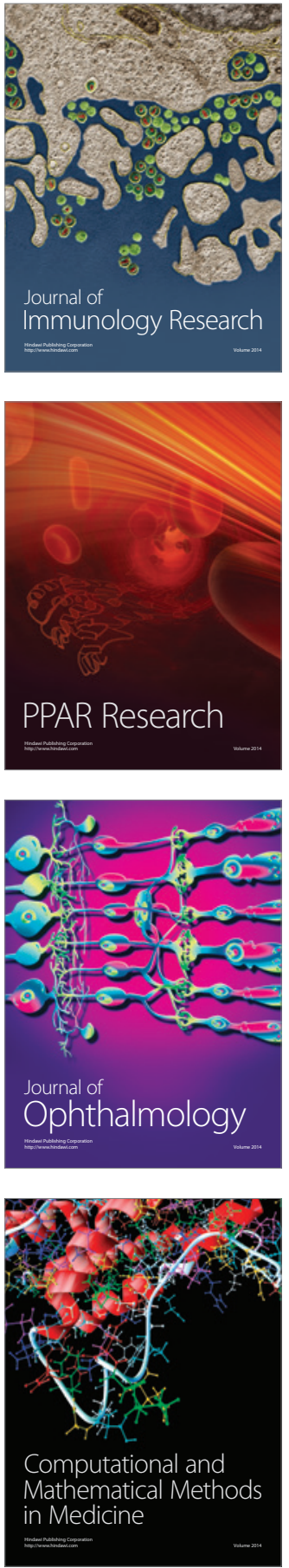

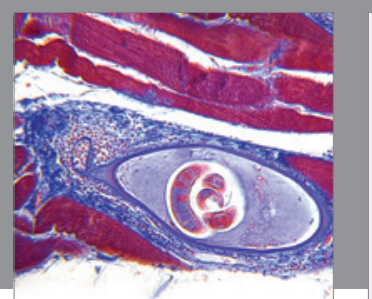

Gastroenterology Research and Practice

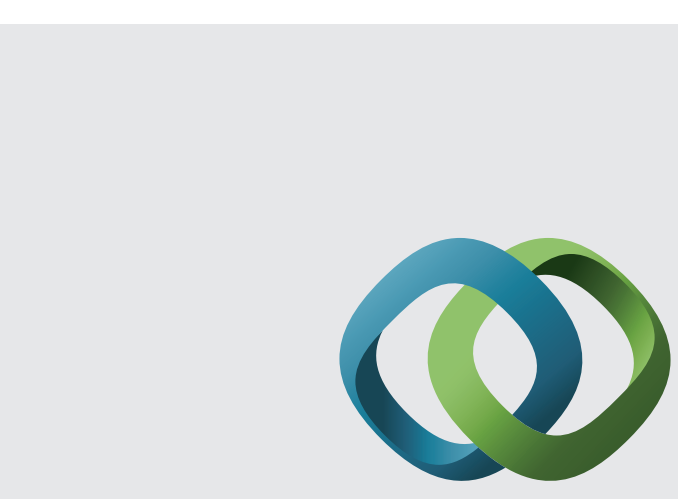

\section{Hindawi}

Submit your manuscripts at

http://www.hindawi.com
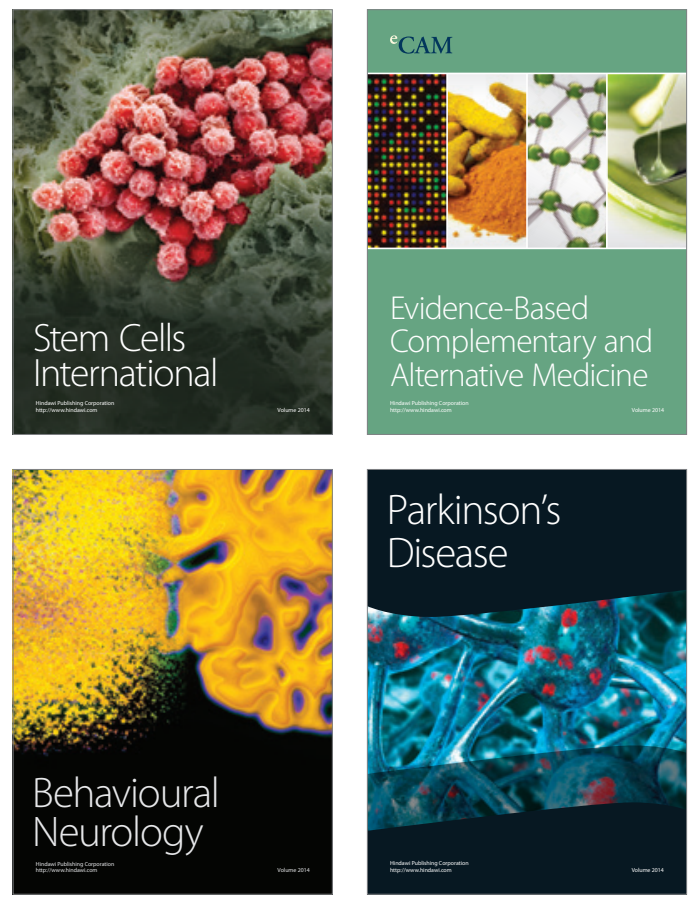
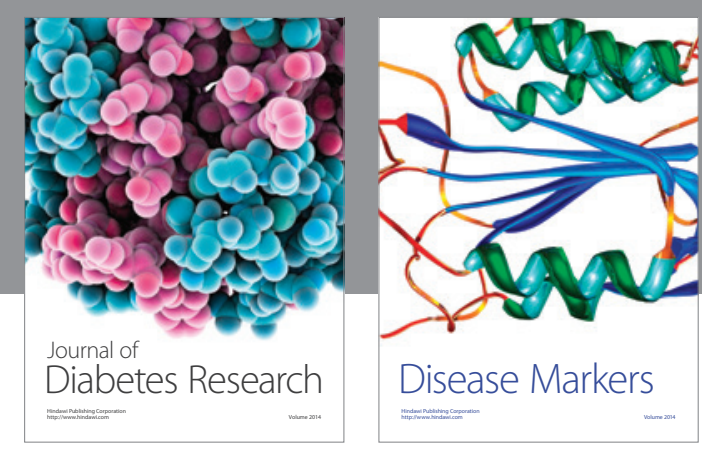

Disease Markers
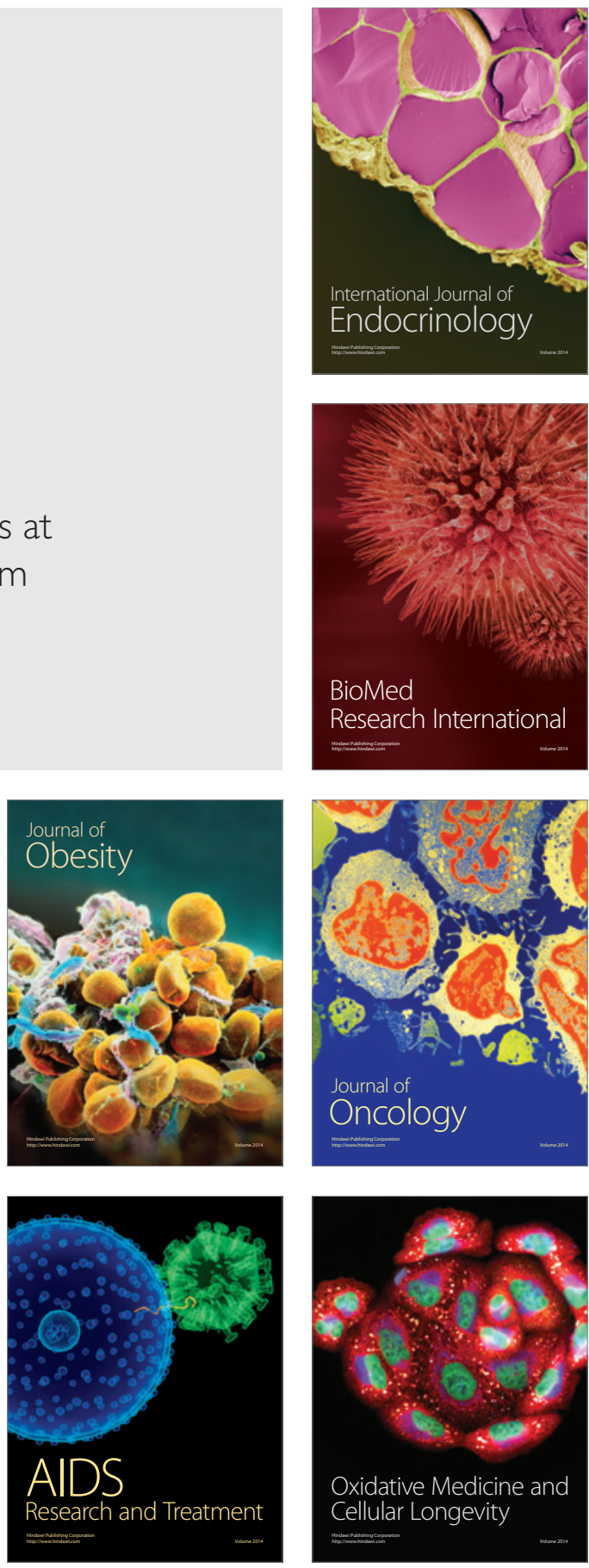